Doubl e- st $r$ anded RNA-act i vated pr ot ei $n$ ki nase (PKR) fused to green $\mathrm{fl}$ uor escent prot ei $\mathrm{n}$ i nduces apopt osi s of human enbryoni c ki dney cel I s: Possi bl e rol e in the Fas si gnal ing pat hway

\begin{tabular}{|l|l|}
\hline 著者 & $\begin{array}{l}\text { Taki zawa Takenor i , Tat enat su Chi zur u, } \\
\text { Nakani shi Yoshi nobu }\end{array}$ \\
\hline $\begin{array}{l}\text { j our nal or } \\
\text { publ i cat i on t i t l e }\end{array}$ & Journal of Bi ochem st ry \\
\hline vol une & 125 \\
\hline number & 2 \\
\hline page r ange & $391-398$ \\
\hline year & 1999- 01-01 \\
\hline URL & ht t p: //hdl . handl e. net /2297/14558 \\
\hline
\end{tabular}




\title{
Double-Stranded RNA-Activated Protein Kinase (PKR) Fused to Green Fluorescent Protein Induces Apoptosis of Human Embryonic Kidney Cells: Possible Role in the Fas Signaling Pathway ${ }^{1}$
}

\author{
Takenori Takizawa,, ${ }^{*}$ Chizuru Tatematsu, ${ }^{*}$ and Yoshinobu Nakanishi ${ }^{\dagger}$ \\ - Department of Biochemistry, Institute for Developmental Research, Aichi Human Service Center, Kasugai, Aichi \\ 480-0392; and ${ }^{\dagger}$ Faculty of Pharmaceutical Sciences, Kanazawa University, Kanazawa, Ishikawa 920-0934 \\ Received September 7, 1998; accepted November 10, 1998
}

\begin{abstract}
PKR is an interferon-inducible, double-stranded (ds) RNA-activated serine/threonine protein kinase, and has been shown to play roles in viral pathogenesis, cell growth and apoptosis. We expressed PKR as a fusion protein with enhanced jellyfish green fluorescence protein (EGFP) in human embryonic kidney 293 cells to visualize the effect of PKR transfection. The EGFP-fusion construct with wild-type PKR showed both auto- and substrate-phosphorylation activities independent of dsRNA, indicating EGFP-PKR is constitutively active. The EGFP-construct with a mutant PKR with the first RNA binding domain deleted still possessed kinase activities. On the other hand, the EGFP-fusion with a catalytically inactive mutant of $P K R$ with the substitution of $K$ at 296 with $R$, which has been shown to have tumorigenic properties, did not possess kinase activities. Transfection of the constitutive active forms of EGFP-PKR constructs induced apoptosis in 293 cells without dsRNA, whereas the EGFP-fusion with the catalytically inactive mutant did not cause apoptosis but rather protected cells from Fas-induced cell death. In addition, Fas-stimulation increased endogenous PKR activities. These results constitute evidence that PKR is sufficient to induce apoptosis, and plays a role in Fas-mediated apoptosis.
\end{abstract}

Key words: apoptosis, EGFP, Fas, PKR, protein kinase.

The interferon-inducible, double-stranded (ds) RNA-activated protein kinase $(\mathrm{PKR})$ is a serine/threonine kinase ubiquitously expressed in mammalian cells $(1,2)$. Human PKR consists of 551 amino acids, as deduced from its cDNA sequence (3), and is divided into two domains; a regulatory domain in the $\mathrm{N}$-terminal half and a catalytic domain in the C-terminal half (4). Two RNA binding domains (RBD) exist in the regulatory domain, and multiple conserved catalytic subdomains characteristic of serine/threonine kinase are located in the catalytic domain (3). PKR is activated by binding to a variety of dsRNA molecules generated during viral infection or by polyanions (2). Upon activation, PKR exhibits two kinase reactions: autophosphorylation of itself, and phosphorylation of substrates which include eukaryotic translational initiation factor 2 $(\mathrm{eIF}-2 \alpha)(5)$, transcription inhibition factor $\mathrm{I} \kappa \mathrm{B}(6)$, and human immunodeficiency virus-encoded tat protein (7). Phosphorylation of eIF-2 $\alpha$ inhibits protein synthesis at the

\footnotetext{
This work was supported in part by Grants-in-Aid for Scientific Research from the Ministry of Education, Science, Sports and Culture of Japan, and by a grant from the Nagase Science and Technology Foundation.

${ }^{2}$ To whom correspondence should be addressed. Phone: +81-568-880811 (Ext. 3592), Fax: +81-568-88-0829, E-mail: takizawa insthsc.pref.aichi.jp

Abbreviations: dsRNA, double-stranded RNA; EGFP, enhanced jellyfish green fluorescence protein; eIF, eukaryotic translational initiation factor; PKR, dsRNA-activated protein kinase; RBD, RNA binding domain.
}

(C) 1999 by The Japanese Biochemical Society. initiation level, thereby inhibiting cell growth or viral replication (4). Thus PKR is thought to participate in the antiviral and antiproliferative actions of interferon $(2,8)$. It was found that the expression of a catalytically inactive mutant of PKR with the substitution of $K$ at 296 with $R$ or a mutant with the RNA-binding domain deleted confers transformation phenotypes upon NIH-3T3 cells, suggesting that PKR functions as a tumor suppresser $(9-11)$. However, the mechanisms by which PKR acts as a tumor suppresser remain to be clarified. Transgenic mice devoid of PKR activity have been generated, but tumors did not spontaneously arise (12), arguing against PKR being a tumor suppresser. On the other hand, PKR overexpression inhibits the growth of yeast cells (13), and induces apoptosis of HeLa cells $(14,15)$. Recent studies have shown that transfection of a vector carrying either an antisense PKR or a trans-dominant negative PKR protected U937 and NIH-3T3 cells from TNF- $\alpha$ - or serum deprivation-induced apoptosis $(16,17)$. Moreover, mouse embryo fibroblasts derived from mutant mice carrying homozygous deletions in the PKR gene were revealed to be resistant to apoptosis in response to double-stranded RNA, TNF- $\alpha$ or lipopolysaccharide (18). These results imply that PKR is involved in stress-induced apoptosis.

Fas (APO-1/CD95) is a transmembrane protein and belongs to the nerve growth factor receptor/tumor necrosis factor receptor superfamily $(19,20)$. The Fas ligand has been cloned and the predicted amino acid sequence revealed it also belongs to the tumor necrosis factor family (21). It is believed to play an essential role in $\mathrm{T}$ cell deletion 
during tolerance. Upon binding of the Fas ligand or agonistic anti-Fas antibodies, Fas undergoes trimerization and induces a cytolytic signal in the cells (22). The activated Fas binds to FADD/MORT1 through its death domain in the cytoplasmic region $(23,24)$, and then FADD/MORT1 binds to FLICE/MACH/Mch5 through the death effector domain in their $\mathrm{N}$-terminal region $(25,26)$, which then activates the downstream caspase cascade (27).

We have suggested that $P K R$ is involved in the induction of Fas expression by influenza virus infection, since a synthetic dsRNA, poly (I)-poly $(\mathrm{C})$, similarly increased the amount of Fas mRNA (28). In addition, the expression of a dominant negative PKR mutant inhibited the augmented expression of Fas as well as apoptosis induced by the virus infection (29). As the besal level of expression of Fas was still observed in the cells transfected with the dominant negative PKR mutant, it seems that PKR plays a role not only in Fas expression but in apoptotic signaling after the virus infection. However, little is known about the relationship between Fas signaling and PKR activation. In the present study, we examined the ability of PKR to induce apoptosis in response to Fas activation, and found that PKR appears to mediate apoptotic signaling in the Fas pathway.

\section{MATERIALS AND METHODS}

Cell Culture and DNA Transfection-Human embryonic kidney 293 (293) and COS-1 cells were cultured in Dulbecco's modified Eagle's medium (D.MEM) supplemented with $10 \%$ fetal bovine serum, and were maintained under $5 \% \mathrm{CO}_{2}$ at $37^{\circ} \mathrm{C}$. Cells were transfected with $2 \mu \mathrm{g}$ of plasmid DNA per $5 \times 10^{5}$ cells using $6 \mu \mathrm{l}$ of Lipofectamineplus and $4 \mu \mathrm{l}$ of Lipofectamine (GibcoBRL, MD, USA) according to the manufacturer's instructions. For microscopic observation, cells were reseeded on celldesk (Sumitomo Bakelite, Japan) in 24-well plates the day after transfection, and then incubated in the presence or absence of anti-Fas monoclonal antibodies for another 2 or 3 days. The cells were then mounted on a slide glass, and the expression of enhanced jellyfish green fluorescence protein (EGFP) was observed and photographed under a fluorescence microscope (Olympus BX-60, Tokyo) at a magnification of 70 .

Antibodies-Anti-human Fas monoclonal antibodies were purchased from Pharmingen (DX2) (San Diego, USA) or MBL (UB2) (Nagoya). Anti-human PKR monoclonal antibodies was generously provided by Dr. Ara Hovanessian (Institut Pasteur, France). Anti-human PKR poly. clonal antibodies (K-17) and anti-GFP polyclonal antibodies were from Santa Cruz Biotechnology (Santa Cruz, USA) and Clontech Laboratories (Palo Alto, USA), respectively.

Plasmids-Human PKR cDNA subcloned into the pBluescript vector (Stratagene, La Jolla, USA) was obtained from Dr. Ara Hovanessian. A mutant PKR cDNA carrying a point mutation of $\mathrm{K}$ at 296 to $\mathrm{R}$ was constructed as described (29). A mutant PKR that lacks the $\mathrm{N}$-terminal region (amino acids 1-97) was constructed by deleting the ScaI-NcoI fragment from the PKR cDNA. A mutant PKR that lacks the $\mathrm{N}$-terminal region (amino acids 1-97) but contains the leucine zipper motif derived from the transcription factor of NFIL6 (amino acids 303-345) was constructed as follows. The DNA fragment containing the leucine zipper motif was obtained by PCR with forward (5'
AAAAGCTTCCTGGAGCTCACGGCCGAGA3') and reverse primers (5'AACCATGGGGCGAGCAGGGGCTCGGGCAG3') using NFIL6 cDNA (30) as a template. The amplified DNA fragment was digested with HindIII and $N c o I$, and then used to replace the HindIII- $N c o$ I fragment of wild PKR cDNA. That the HindIII-NcoI fragment was replaced was verified by DNA sequencing. Wild or mutant PKR cDNA was digested with HindIII and $X b a I$, and then subcloned into the multicloning site of the pEGFP.C3 vector (Clontech Laboratories, Palo Alto, USA) to fuse EGFP to the $\mathrm{N}$-terminus of each PKR construct. The resulting EGFP.PKR fusion proteins contained an additional 16-amino acid sequence derived from the multicloning site of the vector.

In Vitro PKR Assay-PKR activity was measured with minor modifications as described (31). Briefly, PKR in a cell extract was precipitated by incubation with the anti-PKR monoclonal antibodies or anti-GFP polyclonal antibodies, followed by protein-G Sepharose 4FF (Pharmacia LKB Biotechnology, Sweden). The immunoprecipitated PKR was incubated with $\left[\gamma^{32} \mathrm{P}\right] \mathrm{ATP}(650 \mathrm{Ci} / \mathrm{mmol}$, ICN Biomedicals, Irvine, California) in the presence or absence of poly(I)-poly(C) at a concentration of $0.1 \mu \mathrm{g} / \mathrm{ml}$ for 15 $\min$ at $30^{\circ} \mathrm{C}$, and then with $2 \mu \mathrm{g}$ of histone $\mathrm{H} 2 \mathrm{~A}$ (Boehringer Mannheim, Germany), which is an effective substrate for PKR (31), for another $15 \mathrm{~min}$ at $30^{\circ} \mathrm{C}$. The phosphorylation reaction was resolved by SDS.PAGE and visualized by autoradiography.

DNA Fragmentation Assay-DNA was extracted as described (32). Briefly, cells were rinsed twice with PBS and then scraped from the dishes. The cell pellets were resuspended at a density of $2 \times 10^{8} \mathrm{cells} / \mathrm{ml}$ in lysis buffer consisting of $10 \mathrm{mM}$ Tris- $\mathrm{HCl}$ ( $\mathrm{pH} 7.5), 10 \mathrm{mM}$ EDTA, and $0.2 \%$ Triton X-100. After $10 \mathrm{~min}$ on ice, the lysates were centrifuged at $15,000 \mathrm{rpm}$ for $10 \mathrm{~min}$, and the supernatants were extracted with phenol/chloroform and chloroform. After ethanol precipitation and washing with $70 \%$ ethanol, the DNA was resuspended in TE ( $10 \mathrm{mM}$ Tris- $\mathrm{HCl}, \mathrm{pH} 8,1$ $\mathrm{mM}$ EDTA). The samples were then treated with RNase A $(0.6 \mathrm{mg} / \mathrm{ml})$ at $37^{\circ} \mathrm{C}$ for $30 \mathrm{~min}$, and electrophoresed on a $1.6 \%$ agarose gel. After electrophoresis, the gel was stained with ethidium bromide and photographed.

Immunoblot Analysis-Cells were lysed in lysis buffer (33). After heating for $3 \mathrm{~min}$ at $100^{\circ} \mathrm{C}$, the lysates were resolved by SDS-PAGE, and then transferred to Immobilon-P membranes (Millipore, MA, USA). The blots were probed with anti-PKR monoclonal or polyclonal antibodies at a dilution of $1: 1,000$, and then the secondary anti-mouse or anti-rabbit immunoglobulin antibodies, respectively, labeled with horseradish peroxidase at a dilution of 1 : 1,000. Signals were visualized with ECL (Amersham, Buckinghamshire, UK).

\section{RESULTS}

Expression of EGFP-PKR Fusion Proteins-High level expression of wild-type PKR by transfection is not usually possible, probably due to generalized inhibition of protein synthesis. Therefore, ectopic expression of wild-type PKR is mediated by either recombinant vaccinia virus (14), or co-transfection of GFP (17). Moreover, endogenous PKR is superimposed on exogenously transfected PKR of the same species when analyzed by Western blotting, so it seems to 
be difficult to determine the amount of exogenous PKR. To overcome these problems, we have constructed and expressed PKR as a fusion protein with EGFP in cells (Fig. 1). EGFP was fused with wild-type PKR (designated as PKR), or with a mutant PKR in which $296 \mathrm{~K}$ was replaced by $\mathrm{R}$ (designated as $\mathrm{K} / \mathrm{R}$ ). This mutant has been shown to be

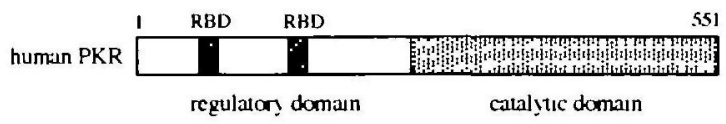

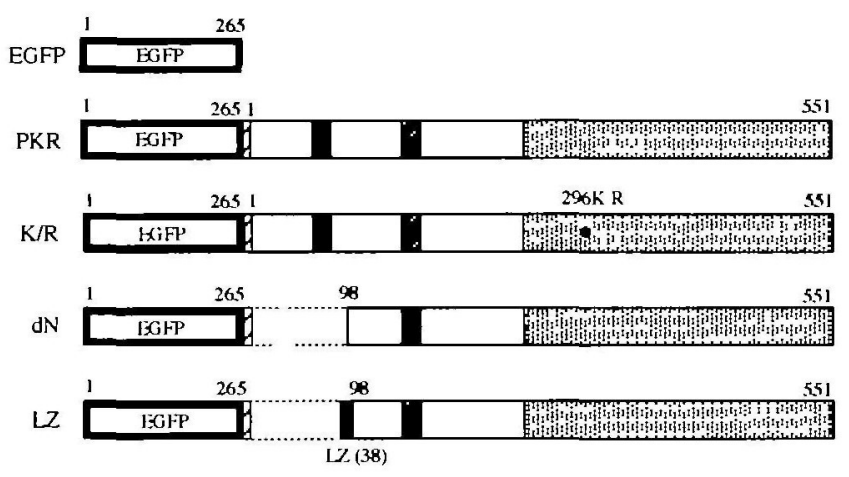

Fig. 1. Schematic representation of the various expression constructs of EGFP-PKR. A schematic representation of human PKR is presented at the top of the figure. The two RNA binding domains are denoted es RBD. EGFP is the enhanced jellyfish green fluorescence protein. PKR denotes the EGFP-fusion with wild-type PKR. K/R denotes the EGFP-fusion with the mutant PKR containing the amino acid substitution of $K$ at 296 to $R$. dN denotes the EGFP-fusion with the mutant PKR, with the $97 \mathrm{~N}$-terminal amino acids deleted, indicated as a dotted line. LZ denotes the EGFP-fusion with the mutant PKR containing the same deletion as $\mathrm{dN}$ but with the leucine zipper motif of NFIL6, which is denoted as LZ. The hatched box after EGFP denotes the amino acid stretch derived from the multicloning sites of the vectors.

(A)

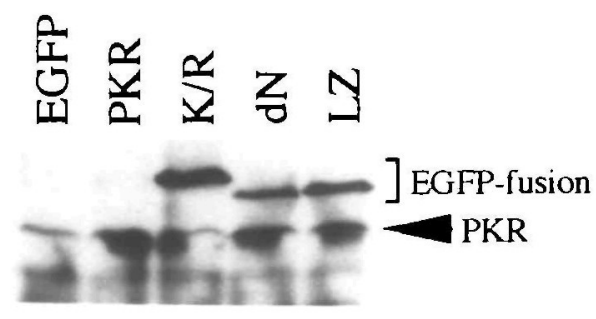

(B)

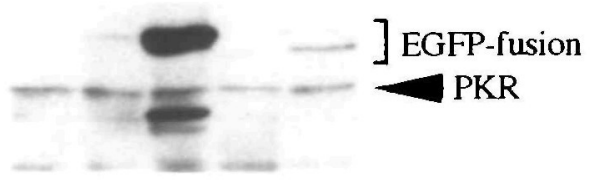

Fig. 2. Expression of the EGFP.PKR fusion constructs in 293 (A) or COS-1 (B) cells. Cells were transfected with $2 \mu \mathrm{g}$ of each plasmid construct as indicated above the lanes, using Lipofectamine reagents according to the manufacturer's instructions. Cells were lysed in lysis buffer $48 \mathrm{~h}$ after transfection. The lysates were then resolved by SDS-PAGE and transferred to Immobilon-P membranes. The blots were probed with anti-PKR polyclonal antibodies (Santa Cruz K-17), followed by anti-rabbit immunoglobulin antibodies labeled with horseradish peroxidase. Signals were visualized with ECL. EGFP-fusion indicates the various positions of EGFP-PKR proteins. PKR indicates the endogenous PKR. dominant negative, and to transform NIH3T3 cells upon transfection $(9,10)$. EGFP was also fused with a mutant PKR with the $\mathrm{N}$-terminal region (amino acids 1-97) including the first RNA-binding domain (designated as $\mathrm{dN}$ ) deleted. This mutant has also been shown to be tumorigenic (11). The EGFP fusion designated as LZ has a mutant PKR with the $\mathrm{N}$-terminal region deleted as $\mathrm{dN}$, but retains the leucine zipper motif of NFTL6 (amino acids 303-345) (30). $\mathrm{PKR}$ has been suggested to undergo dimerization when it is activated by dsRNA. Since the leucine zipper motif acts to form homodimers, LZ could become constitutively active on dimerization without dsRNA. Expression of these EGFP-PKR fusion proteins could be easily detected on

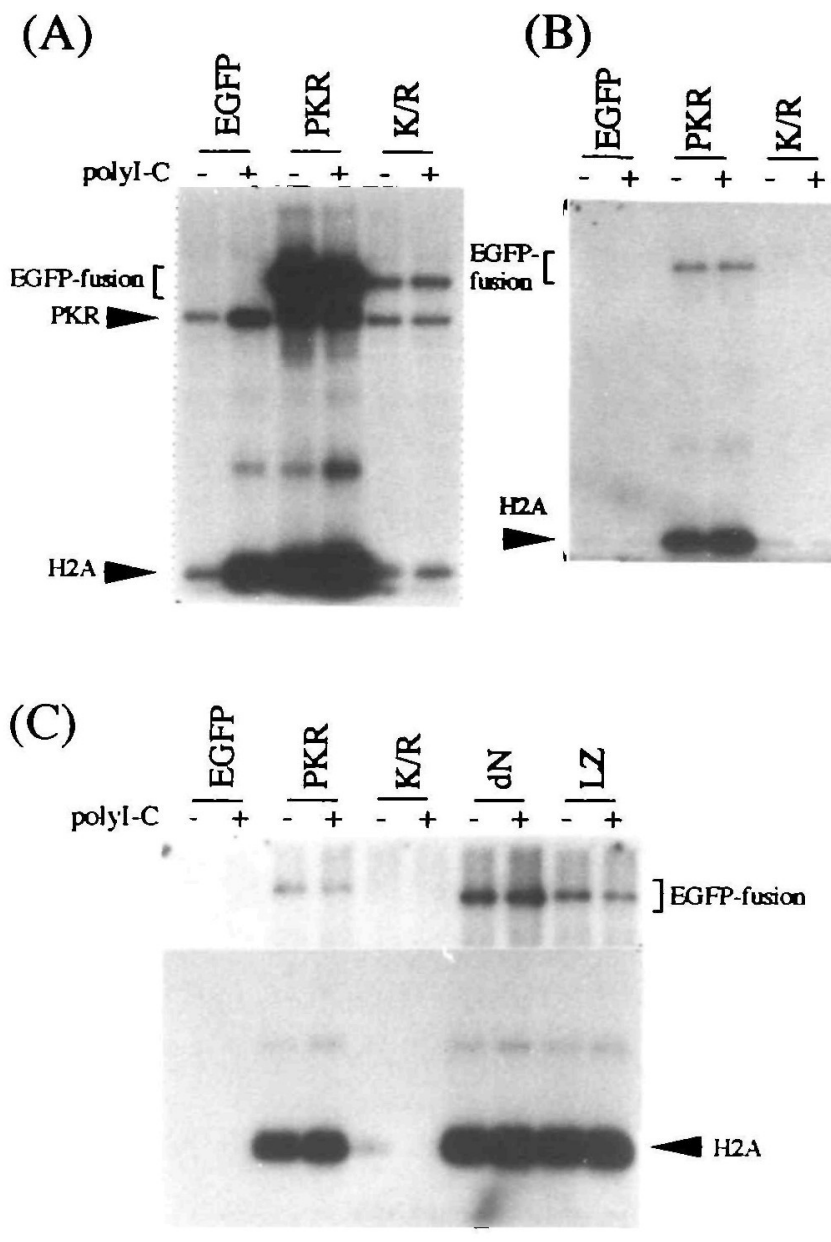

Fig. 3. In vitro kinase activity of EGFP-PKR fusion proteins. The EGFP-PKR fusion proteins in aliquots of the lame lysates of 293 (A and C) or COS-1 (B) cells as those used in Fig. 2 were immunoprecipitated with anti-PKR monoclonal antibodies (A and B) or anti-GFP polyclonal antibodies (Clontech) (C), followed by protein-G Sepharose 4FF. The immunoprecipitated PKR was incubated with $\left[\gamma-{ }^{32} \mathrm{P}\right] \mathrm{ATP}$ in the presence $(+)$ or absence $(-)$ of poly $(\mathrm{I})$-poly $(\mathrm{C})$, as indicated above the lanes, at a concentration of $0.1 \mu \mathrm{g} / \mathrm{ml}$ for $15 \mathrm{~min}$ at $30^{\circ} \mathrm{C}$, and then with $2 \mu \mathrm{g}$ of histone $\mathrm{H} 2 \mathrm{~A}$ for another $15 \mathrm{~min}$ at $30^{\circ} \mathrm{C}$. The phosphorylation reaction was resolved by SDS.PAGE and visualized by autoradiography. EGFP-fusion indicates the various positions of EGFP.PKR proteins. PKR indicates the endogenous PKR. $\mathrm{H} 2 \mathrm{~A}$ indicates the histone H2A. In (C), the upper panel shows an autoradiogram obtained on long exposure for $17 \mathrm{~h}$ at room temperature, while the lower panel shows one on short exposure for $7.5 \mathrm{~h}$ at room temperature of the same gel. 
either fluorescent microscopy or Western blotting because of their larger molecular weights than that of endogenous PKR.

The expression of the EGFP-wild or a mutant PKR fusion protein in 293 or COS-1 cells was examined by Western blotting using anti-PKR polyclonal antibodies raised against a peptide corresponding to amino acids 521-537 of human PKR (Fig. 2, A and B). As expected, PKR was poorly expressed in these cells (the relative intensity of EGFP. PKR expressed as a ratio to the endogenous PKR in 293 cells was 0.23 , as determined by scanning the film), whereas a significant amount of $K / R$ was observed ( 8.0 in 293 cells) (Fig. 2). This seems to be consistent with a previous report that dominant negative mutants of $\mathrm{PKR}$
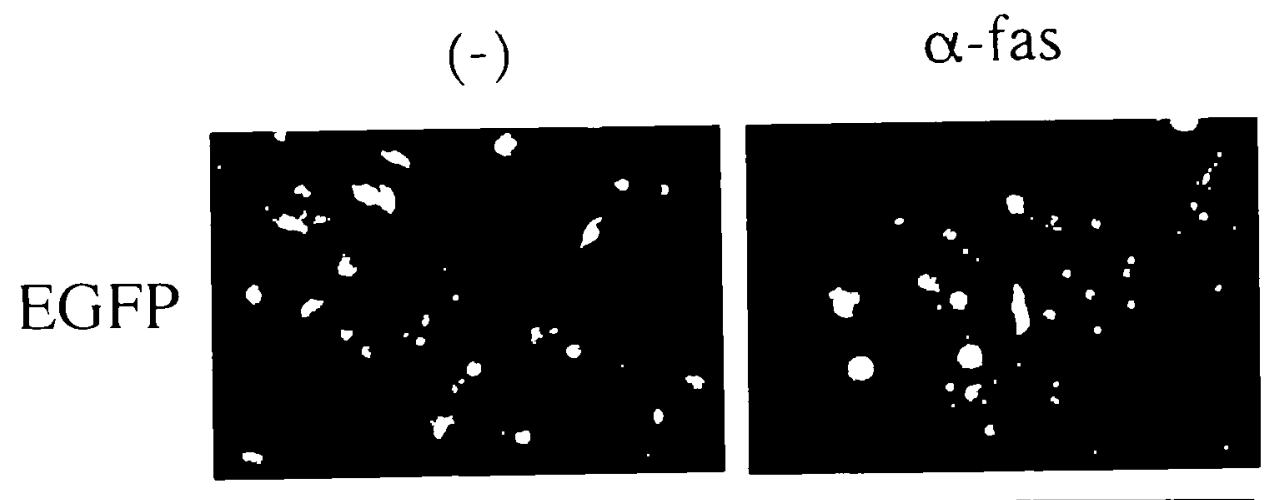

PKR
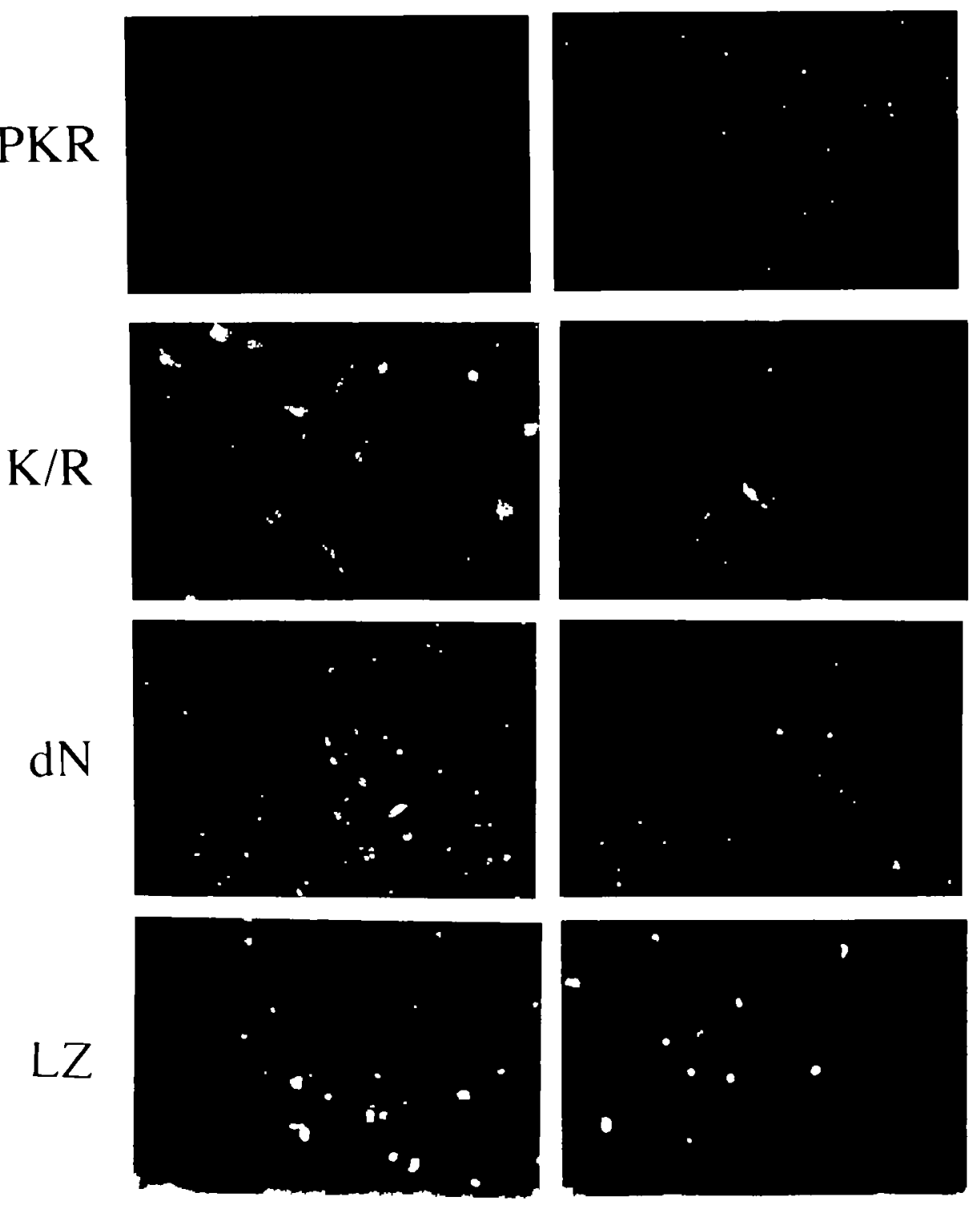

Fig. 4. Expression of the EGFPPKR fusion constructs in 293 cells. Cells were transfected with plasmid constructs as indicated. The cells were reseeded on celldesk (Sumitomo Bakelite) in 24-well plates the day after transfection and then incubated for another 2 days in the presence $(\alpha-$ Fas) or absence $(-)$ of anti.Fas monoclonal antibodies (Pharmingen) at $300 \mathrm{ng} / \mathrm{ml}$. The cells were then mounted on a slide glass and then photographed under a fluorescence microscope (Olympus) at a magnification of 70 . The pictures of PKR and dN were overexposed to visualize the expression of these constructs. 
were overexpressed in COS- 1 cells (34). $\mathrm{dN}$ and LZ were poorly or moderately expressed in COS-1 ( 0.38 and 0.72 , respectively) or 293 cells (1.18 and 1.61 , respectively) (Fig. 2, A and B), suggesting that $\mathrm{dN}$ and LZ have some kinase activities. The amount of endogenous PKR did not significantly change on transfection of these constructs (Fig. 2). To determine whether or not these EGFP fusions have enzyme activities, the auto- and substrate phosphorylation activities of PKR in the same extracts as used for the immunoblotting were assayed. Since the anti-PKR polyclonal antibodies used for immunoblotting was not suitable for the immunoprecipitation of PKR followed by the kinase reaction, anti-PKR monoclonal antibodies which recognizes the $\mathrm{N}$-terminal region was first employed (31). In the control EGFP-transfected 293 cells, endogenous PKR activity was effectively stimulated upon poly(I)-poly(C) addition, which caused autophosphorylation (3.0-fold activation) and phosphorylation of histone H2A (4.0-fold activation) as a substrate (Fig. 3A). EGFP-PKR caused significant autophosphorylation and histone H2A phosphorylation without poly(I)-poly $(\mathrm{C})$ addition, whereas in $\mathrm{K} /$ $\mathrm{R}$-transfected cells, the activities of both $\mathrm{K} / \mathrm{R}$ and endogenous PKR were similar to that of a control without poly(I) -poly(C). Moreover, endogenous PKR in K/R-transfected cells was not activated by poly $(\mathrm{I})$-poly $(\mathrm{C})$, indicating that $\mathrm{K} / \mathrm{R}$ dominant-negatively suppresses endogenous PKR activities in vitro. Since the anti-PKR monoclonal antibodies did not precipitate endogenous PKR of COS-1 cells, an effect of endogenous PKR on the kinase reaction of EGFP.PKR constructs could be eliminated (Fig. 3B). PKR showed both auto- and H2A-phosphorylation activities independent of poly(I)-poly(C), although they were much lower than those in 293 cells (Fig. 3B). K/R did not show any kinase activities in an extract of COS-1 cells, in contrast to that in 293 cells. These results suggested that the significant activation of PKR and slight activities of $\mathrm{K} /$ $R$ in 293 cells are due to the effect of endogenous PKR. This seems to be consistent with the previous report that PKR itself is a good substrate of PKR (35). To examine mutants that lack the N-terminal region, $\mathrm{dN}$ or LZ was immuno. precipitated with anti-GFP polyclonal antibodies, and then kinase activities were assayed (Fig. $3 \mathrm{C}$ ). $\mathrm{dN}$ and $\mathrm{LZ}$ exhibit auto- and substrate phosphorylation activities independent of poly $(\mathrm{I})$-poly $(\mathrm{C})$. The relative intensities of autophosphorylation of $\mathrm{dN}$ and $\mathrm{LZ}$ without poly $(\mathrm{I})$ - $\operatorname{poly}(\mathrm{C})$ were 2.0 and 1.7, respectively, compared with that of PKR, while the relative expression levels of $\mathrm{dN}$ and $\mathrm{LZ}$ were 5.1 and 7.0 compared to that of PKR, respectively (Fig. 2A). Therefore these mutants may have roughly half to one-third the enzyme activity of wild-type PKR. Since endogenous and exogenous PKR molecules exist simultaneously in the cytosol of PKR-transfected cells, the kinase activities observed in the extract of 293 cells seem to reflect the actual activities of EGFP-PKR fusion constructs. Thus, the EGFP tag may make PKR constructs, except $K / R$, constitutively active when transfected into 293 cells, while $\mathrm{K}$ / $\mathrm{R}$ still retained a dominant negative character, at least in vitro.

Induction of Apoptosis by EGFP-PKR Fusion ProteinsThe effect of an EGFP.PKR fusion construct on the death of 293 cells was next examined. The expression of an EGFP fusion was easily detected on fluorescence microscopy (Fig. 4 ), and the numbers of cells exhibiting the characteristic morphological changes of apoptosis, i.e. shrinkage and rounding, were determined in several fields (Fig. 5A). While EGFP-transfected control cells did not show remarkable cell rounding or shrinkage (about $18 \%$ in Fig. 5A), many cells underwent apparent apoptosis (about 80\%) in the presence of anti-Fas antibodies. In contrast to the controls, only a small number of PKR-, dN-, or LZ-transfected cells were fluorescence positive, with much lower intensity than that in control cells, which was consistent with the results of immunoblotting. It should be mentioned
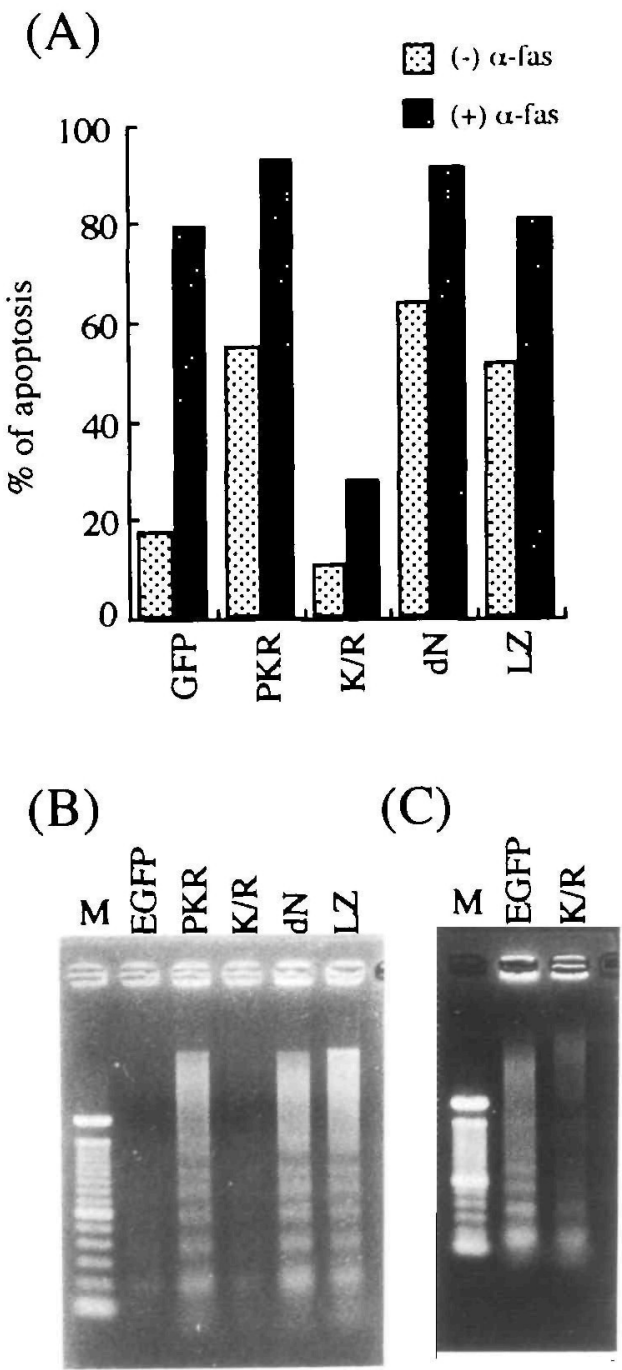

Fig. 5. The effect of EGFP-PKR fusion constructs on the death of 293 cells. (A) Cells were transfected with plasmid constructs, as indicated, and then photographed as described in Fig. 4. The number of fluorescent cells was determined in several photographs. Shrunken and rounded cells were scored as apoptotic, and their ratio to the total fluorescent cells was determined. The values are the means for three independent experiments. (B and C) Cells were transfected with plasmid constructs, as indicated above the lanes, and then cultured in the absence (B) or presence (C) of anti-Fas monoclonal antibodies (Pharmingen) at a concentration of $300 \mathrm{ng} / \mathrm{ml}$ for $36 \mathrm{~h}$. Then chromosome DNA was prepared by phenol/chloroform extraction followed by ethanol precipitation. The DNA samples were treated with RNaseA and then electrophoresed on a 1.6\% agarose gel. After electrophoresis, the gel was stained with ethidium bromide and photographed. Lanes $\mathrm{M}$ indicate the 100 -bp ladder marker. 
that the pictures of PKR and LZ were overexposed to visualize the expression of these constructs (Fig. 4). In addition, more than $50 \%$ of fluorescence positive cells exhibited shrinkage and rounding even in the absence of anti-Fas antibodies (about 56, 65, and 56\% of PKR-, dN-, and LZ-transfected cells, respectively), and most cells underwent apoptosis in the presence of the antibodies (about 94, 93, and 82\% of PKR-, dN-, and LZ-transfected cells, respectively). On the other hand, the number of $K / R$ positive cells was almost the same as that of control ones, with a significant level of intensity, and fewer K/R-transfected cells showed apoptotic changes, even in the presence of anti-Fas antibodies (about 11 and $28 \%$ in the absence and presence of anti-Fas antibodies, respectively). To further determine whether or not the above morphological changes were due to apoptosis, the fragmentation of chromosomal DNA into oligomers, another apoptotic marker, was examined. As shown in Fig. 5B, transfection of PKR, dN, or LZ in to 293 cells caused characteristic DNA fragmentation, indicating that the above morphological changes were due to apoptosis, whereas that of EGFP alone or $\mathrm{K} / \mathrm{R}$ did not. In addition, transfection of $\mathrm{K} / \mathrm{R}$ reduced the degree of DNA fragmentation induced by anti-Fas antibodies. Transfection of the constructs used in this study into 293 cells did not alter Fas expression on the cell surface, which was analyzed by flowcytometry (data not shown). This indicated that the effect of EGFP-PKR constructs on apoptosis in response to Fas is not secondary to the altered Fas expression.

\section{(A)}

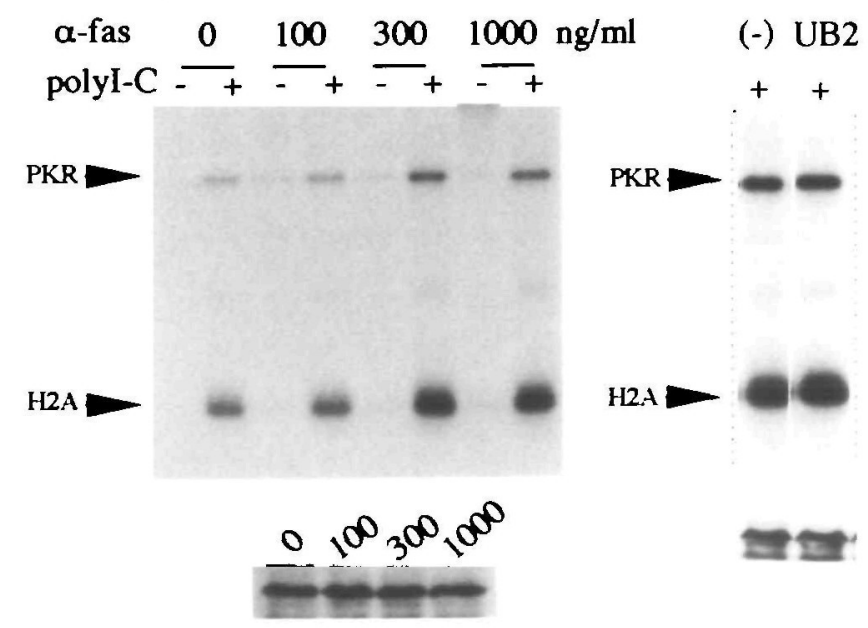

Fig. 6. PKR activity in cells after exposure to anti-Fas monoclonal antibodies. (A) 293 cells were cultured for $12 \mathrm{~h}$ in the presence of agonistic anti-Fas monoclonal antibodies (Pharmingen) at various concentrations, as indicated above the lanes, and then lysates were prepared, and the in vitro auto- (PKR) and substrate (H2A) phosphorylation activities were determined in the presence $(+)$ or absence (-) of poly(I)-poly(C) at $0.1 \mu \mathrm{g} / \mathrm{ml}$, as described in Fig. 3 . An autoradiograph after $12 \mathrm{~h}$ exposure at room temperature is shown. (B) 293 cells were cultured for $12 \mathrm{~h}$ in the presence or absence $(-)$ of control anti-Fas monoclonal antibodies (UB2, MBL) at a concentration of $300 \mathrm{ng} / \mathrm{ml}$. Then lysates were prepared and PKR activities were determined in the presence of poly $(1)$-poly $(C)$ at $0.1 \mu \mathrm{g} / \mathrm{ml}$. An autoradiograph after $16 \mathrm{~h}$ exposure at room temperature is shown. Portion of the same lysates was subjected to immunoblotting analysis with anti-PKR monoclonal antibodies (lower panel).
Fas Stimulation Activates $P K R-$ We finally examined whether the Fas activation stimulates endogenous PKR activity or not. Extracts of 293 cells were prepared $12 \mathrm{~h}$ after cultivation in the presence of various amounts of anti-Fas antibodies, and then PKR activities were assayed (Fig. 6A). Anti-Fas antibodies at a concentration of $300 \mathrm{ng} /$ $\mathrm{ml}$ or more increased the auto- and substrate phosphorylation activities of PKR, while the total amount of PKR did not change, as judged on immunoblotting (Fig. 6A). Control anti-Fas antibodies (UB2), which does not induce apoptosis, did not alter the PKR activities or amounts (Fig. 6B), suggesting that $\mathrm{PKR}$ activation is specific to the apoptosis signal in response to Fas.

\section{DISCUSSION}

So far, PKR or a mutant form of it has been expressed as a fusion protein with TrpE, glutathione S-transferase (GST), or Gal4 in either Escherichia coli or yeast cells $(6,36,37)$. We expressed PKR as a fusion protein with EGFP. As GFP does not appear to interfere with cell growth or function (38), we consider that the effect of an EGFP.PKR construct on cell growth is due to the PKR structure. As shown previously, the kinase activity of recombinant GST-PKR purified from $E$. coli did not depend on dsRNA $(6,37)$. Similarly, EGFP.PKR phosphorylates itself and H2A in a dsRNA-independent manner. Moreover, the EGFP-fusion with the mutant PKR with the first RBD deleted, which has been shown to abrogate the RNA binding ability and to have tumorigenic properties (11), also showed the kinase active phenotype independent of dsRNA. A previous study showed that although the PKR mutant with the first RBD deleted loses the dsRNA response, it is still active in the presence of a very high dose of dsRNA or an other polyanion such as heparin (11). Since, native GFP was shown to self-associate into dimers (39), the EGFP-tag may help an EGFP-PKR fusion to associate and dimerize, which results in activation of the fusion construct even in the absence of the first RBD in the $\mathrm{N}$-terminal region. The LZ motif was thus revealed to be unnecessary for the dimerization of PKR in an EGFPfusion construct.

PKR has been implicated in the apoptosis induced by TNF- $\alpha$, poly(I)-poly(C), interferon, lipopolysaccharide, and Fas (this study). Consistent with previous reports (14, 17), we showed that the kinase active forms of EGFP.PKR constructs (PKR, dN, and LZ) are sufficient to induce apoptosis in 293 cells, whereas a kinase inactive mutant $(\mathrm{K} / \mathrm{R})$ is not able to induce it, indicating that enzyme activity is necessary for the induction of apoptosis. A recent study suggested that PKR-induced apoptosis is mediated through eIF2 $\alpha$ phosphorylation, since forced expression of a nonphosphorylated mutant of eIF $2 \alpha$ protected cells from apoptosis in response to TNF- $\alpha$, whereas a mutant which mimics phosphorylated eIF $2 \alpha$ is able to induce apoptosis by itself (17). On the other hand, apoptosis due to infection by recombinant vaccinia virus carrying wild-type PKR was completely inhibited on coinfection of recombinant vaccinia virus expressing bcl-2 without preventing translational inhibition (40). This suggests that bcl-2 is downstream of eIF $2 \alpha$ in the apoptotic pathway.

The interleukin- $1 \beta$-converting enzyme (ICE)-related cysteine protease family (caspases) is essential in many kinds of apoptosis (27) including the Fas and TNF- $\alpha$ 
signaling pathways (22), and caspase-3-activated DNase (CAD) has been shown to mediate Fas-induced DNA fragmentation (41). PKR overexpression induces DNA fragmentation, and has been shown to cause cleavage of one of the death substrates, PARP (40), which caspase-3 is able to cleave $(42,43)$. Therefore, PKR seems to activate caspase-3-like proteases. On the other hand, caspase-3 seems not to be essential for apoptotic morphological changes, since a peptide inhibitor for caspase-3 or an inhibitor of CAD (ICAD) did not inhibit the apoptotic morphological changes (44). PKR transfection causes apoptotic morphological changes as well as DNA fragmentation, suggesting that not only caspase-3-like proteases but also other caspases are involved in PKR-induced apoptosis.

PKR thus seems to be a general transducer of apoptosis. However, it remains to be determined what mechanism(s) increases PKR activities in response to Fas stimulation even in the absence of a viral infection, and how PKR causes downstream apoptotic changes. It has been shown that members of the MAP kinase superfamily, e.g. c-Jun N. terminal kinase/stress-activated protein kinase (JNK/ SAPK) and p38, are activated in the Fas signaling pathway, with some relation to caspases $(45-47)$. To answer the above questions, it is important to determine whether PKR has some linkage to the JNK/SAPK and p38 pathways or not. Our EGFP.PKR fusion system may be a useful tool for such a study.

We are grateful to Dr. Ara Hovanessian for providing the anti-PKR monoclonal antibodies and PKR cDNA, and Dr. Shizuo Akira for the NFIL6 cDNA. We also thank Drs. Katsuhisa Nakajima and Eri Nobusawa for the helpful discussions and support.

\section{REFERENCES}

1. Hovanessian A.G. (1989) The double stranded RNA-activated protein kinase induced by interferon: dsRNA.PK. J. Interferon Res. 9, 641-647

2. Williams, B.R.G. (1995) The role of the dsRNA-activated kinase, PKR, in signal transduction. Semin. Virol. 6, 191-202

3. Meurs, E., Chong, K., Galabru, J., Thomas, N.S.B., Kerr, I.M., Williams, B.R.G., and Hovanessian, A.G. (1990) Molecular cloning and characterization of the human double-stranded RNA activated protein kinase induced by interferon. Cell 62, 379-390

4. Samuel, C.E. (1993) The eIF-2 $\alpha$ protein kinases, regulators of translation in eukaryotes from yeasts to humans. J. Biol. Chem. 268, 7603-7606

5. Samuel, C.E. (1979) Mechanism of interferon action: Phosphorylation of protein synthesis initiation factor eIF-2 in interferon. treated human cells by a ribosome-associated protein kinase possessing site-specificity similar to hemin-regulated rabbit reticulocyte kinase. Proc. Natl. Acad. Sci. USA 76, 600-604

6. Kumar, A., Haque, J., Lacoste, J., Hiscott, J., and Williams, B.R.G. (1994) Double-stranded RNA-dependent protein kinase activates transcription factor NF- $x$ B by phosphorylating $\mathrm{I} x \mathrm{~B}$. Prac. Natl. Acad. Sci. USA 91, 6288-6292

7. Brand, S.R., Kobayashi, R., and Mathews, M.B. (1997) The Tat protein of human immunodeficiency virus type $I$ is a substrate and inhibitor of the interferon-induced, virally activated protein kinase, PKR. J. Biol. Chem. 272, 8388-8395

8. Samuel, C.E. (1991) Antiviral actions of interferon, interferonregulated cellular proteins and their surprisingly selective antiviral activities. Virology 183, 1-11

9. Koromilas, A.E., Roy, S., Barber, G.N., Katze, M.G., and Sonenberg, N. (1992) Malignant transformation by a mutant of the IFN-inducible dsRNA-dependent protein kinase. Science 257, 1685-1689
10. Meurs, E.F., Galabru, J., Barber, G.N., Katze, M.G., and Hovanessian, A.G. (1993) Tumor suppresser function of the interferon-induced double-stranded RNA-activated protein kinase. Proc. Natl. Acad. Sci. USA 90, 232-236

11. Barber, G.N., Wambach, M., Thompson, S., Jagus, R., and Katze, M.G. (1995) Mutants of the RNA.dependent protein kinase (PKR) lacking double-stranded RNA binding domain I can act as transdominant inhibitors and induce malignant transfor. mation. Mol. Cell. Biol. 15, 3138-3146

12. Yang, Y.L., Reis, L.F.L., Pavlovic, J., Aguzzi, A., Sch甘fer, R., Kumar, A., Williams, B.R.G., Aguet, M., and Weissmann, C. (1995) Deficient signaling in mice devoid of double-stranded RNA-dependent protein kinase. EMBO J. 14, 6095-6106

13. Chong, K.L., Feng, F., Schappert, K., Meurs, E., Donahue, T.F., Friesen, J.D., Hovanessian, A.G., and Williams, B.R.G. (1992) Human p68 kinase exhibits growth suppression in yeast and homology to the translational regulator GCN2. EMBO J. 11, 1553-1562

14. Lee, S.B. and Esteban, M. (1994) The interferon-induced double-stranded RNA activated protein kinase induces apoptosis. Virology 189, 491-496

15. Kibler, K.V., Shors, T., Perkins, K.B., Zeman, C.C., Banaszak, M.P., Biesterfeldt, J., Langland, J.O., and Jacobs, B.L. (1997) Double-stranded RNA is a trigger for apoptosis in vaccinia virus-infected cells. J. Virol. 71, 1992-2003

16. Yeung, M.C., Liu, J., and Lau, A.S. (1996) An essential role for the interferon-inducible, double-stranded RNA-activated protein kinase PKR in the tumor necrosis factor-induced apoptosis in U937 cells. Proc. Natl. Acad. Sci. USA 93, 12451-12455

17. Srivastava, S.P., Kumar, K.U., and Kaufman, R.J. (1998) Phosphorylation of eukaryotic translation initiation factor 2 mediates apoptosis in response to activation of the doublestranded RNA-dependent protein kinase. J. Biol. Chem. 273, 2416-2423

18. Der, S.D., Yang, Y.L., Weissmann, C., and Williams, B.R.G. (1997) A double-stranded RNA-activated protein kinase-dependent pathway mediating stress-induced apoptosis. Proc. Natl. Acad. Sci. USA 94, 3279-3283

19. Itoh, N., Yonehara, S., Ishii, A., Yonehara, M., Mizushima, S-1., Sameshima, M., Hase, A., Seto, Y., and Nagata, S. (1991) The polypeptide encoded by the cDNA for human cell surface antigen Fas can mediate apoptosis. Cell 66, 233-243

20. Oehm, A., Behrmann, I., Falk, W., Pawlita, M., Maier, G., Klas, C., Li-Weber, M., Richards, S., Dhein, J., Trauth, B.C., Ponstingl, H., and Krammer, P.H. (1992) Purification and molecular cloning of the APO-1 cell surface antigen, a member of the tumor necrosis factor/nerve growth factor receptor superfamily. J. Biol. Chem. 267, 10709-10715

21. Suda, T., Takahashi, T., Golstein, P., and Nagata, S. (1993) Molecular cloning and expression of the Fas ligand, a novel member of the tumor necrosis factor family. Cell 75, 1169-1178

22. Nagata, S. (1997) Apoptosis by death factor. Cell 88, 355-365

23. Chinnaiyan, A.M., O'Rourke, K., Tewari, M., and Dixit, V.M. (1995) FADD, a novel death domain-containing protein, interacts with the death domain of Fas and initiates apoptosis. Cell 81, 505-512

24. Boldin, M.P., Varfolomeev, E.E., Pancer, Z., Mett, I.L., Camonis, J.H., and Wallach, D. (1995) A novel protein that interacts with the death domain of Fas/APO1 contains a sequence motif related to the death domain. J. Biol. Chem. 270, 77957798

25. Boldin, M.P., Goncharov, T.M., Goltsev, Y.V., and Wallach, D. (1996) Involvement of $\mathrm{MACH}$, a novel MORT1/FADD-interacting protease, in Fas/AP0-1 and TNF receptor-induced cell death. Cell 85, 803-815

26. Muzio, M., Chinnaiyan, A.M., Kischkel, F.C., O'Rourke, K., Shevchenko, A., Scaffidi, C., Bretz, J.D., Zhang, M., Gentz, R., Mann, M., Krammer, P.H., Peter, M.E., and Dixit, V.M. (1996) FLICE, a novel FADD-homologous ICE/CED-3-like protease, is recruited to the CD95 (Fas/APO-1) death-inducing signaling complex. Cell 85, 817-827

27. Cohen, G.M. (1997) Caspases: the executioners of apoptosis. 
Blochem. J. 326, 1-16

28. Takizawa, T., Fukuda, R., Miyawaki, T., Ohashi, K., and Nakanishi, Y. (1995) Activation of the apoptotic Fas antigen-encoding gene upon influenza virus infection involving spontaneously produced beta-interferon. Virology 209, 288-296

29. Takizawa, T., Ohashi, K., and Nakanishi, Y. (1996) Possible involvement of double-stranded RNA-activated protein kinase $(\mathrm{PKR})$ in the cell death by influenza virus infection. $J$. Virol. 70, 8128-8132

30. Akira, S., Isshiki, H., Sugita, T., Tanabe, O., Kinoshita, S., Nishio, Y., Nakajima, T., Hirano, T., and Kishimoto, T. (1990) A nuclear factor for IL-6 expression (NF-IL6) is a member of a C/ EBP family. EMBO J. 9, 1897-1906

31. Galabru, J. and Hovanessian, A.G. (1987) Autophosphorylation of the protein kinase dependent on double-stranded RNA. J. Biol. Chem. 262, 15538-15544

32. Ishida, Y., Agata, Y., Shibahara, K., and Honjo, T. (1992) Induced expression of PD-1 a novel member of the immunoglobulin gene superfamily, upon programmed cell death. EMBO J. 11, 3887-3895

33. Laemmli, U. (1970) Cleavage of structural proteins during the assembly of the head of bacteriophage T4. Nature 227, 680-685

34. Barber, G.N., Wambach, M., Wong, M.L., Dever, T.E., Hinnebusch, A.G., and Katze, M.G. (1993) Translational regulation by the interferon-induced double-stranded-RNA-activated $68-\mathrm{kDa}$ protein kinase. Proc. Natl. Acad. Sci. USA 90, 4621-4625

35. Thomis, D.C. and Samuel, C.E. (1993) Mechanism of interferon action: evidence for intermolecular autophosphorylation and autoactivation of the interferon-induced, RNA-dependent protein kinase PKR. J. Virol. 67, 7695-7700

36. McCormick, S.J., Thomis, D.C., and Samuel, C.E. (1992) Mechanism of interferon action: identification of a RNA binding domain within the $\mathrm{N}$-terminal region of the human RNA-dependent P1/eIF-2 $\alpha$ protein kinase. Virology 188, 47-56

37. Rende-Fournier, R., Ortega, L.G., George, C.X., and Samuel, C.E. (1997) Interaction of the human protein kinase PKR with the mouse PKR homolog occurs via the $\mathrm{N}$-terminal region of PKR and does not inactivate autophosphorylation activity of mouse PKR. Virology 238, 410-423

38. Chalfie, M., Tu, Y., Euskirchen, G., Ward, W.W., and Prasher,
D.C. (1994) Green fluorescent protein as a marker for gene expression. Science 263, 802-805

39. Morise, H., Shimomura, O., Johnson, F.H., and Winant, J. (1974) Intermolecular energy transfer in the bioluminescent system of Aequorea. Biochemistry 13, 2656-2662

40. Lee, S.B., Rodriguez, D., Rodriguez, J.R., and Esteban, M. (1997) The apoptosis pathway triggered by the interferoninduced protein kinase $\mathrm{PKR}$ requires the third basic domain, initiates upstream of $\mathrm{Bcl}-2$, and involves ICE-like proteases. Virology 231, 81-88

41. Enari, M., Sakahira, H., Yokoyama, H., Okawa, K., Iwamatsu, A., and Nagata, S. (1998) A caspase-activated DNase that degrades DNA during apoptosis, and its inhibitor ICAD. Nature 391, 43-50

42. Nicholson, D.W., Ali, A., Thornberry, N.A., Vaillancourt, J.P., Ding, C.K., Gallant, M., Gareau, Y., Griffin, P.R., Labelle, M., Lazebnik, Y.A., Munday, N.A., Raju, S.M., Smulson, M.E., Yamin, T.-T., Yu, V.L., and Miller, D.K. (1995) Identification and inhibition of the ICE/CED-3 protense necessary for mam malian apoptosis. Nature 376, 37-43

43. Tewari, M., Quan, L.T., O'Rourke, K., Desnoyers, S., Zeng, Z., Beidler, D.R., Poirier, G.G., Salvesen, G.S., and Dixit, V.M. (1995) Yama/CPP32 $\beta$, a mammalian homolog of CED-3, is a crmA-inhibitable protease that cleaves the death substrate poly(ADP-ribose) polymerase. Cell 81, 801-809

44. Sakahira, H., Enari, M., and Nagata, S. (1998) Cleavage of CAD inhibitor in CAD activation and DNA degradation during apoptosis. Nature 391, 96-99

45. Yang, X., Khosravi-Far, R., Chang, H.Y., and Baltimore, D. (1997) Daxx, a novel Fas-binding protein that activates JNK and apoptosis. Cell 89, 1067-1076

46. Juo, P., Kuo, C.J., Reynolds, S.E., Konz, R.F., Raingeaud, J., Davis, R.J., Biemann, H.P., and Blenis, J. (1997) Fas activation of the p38 mitogen-activated protein kinase signaling pathway requires ICE/CED-3 family proteases. Mol. Cell. Biol. 17, 24-35

47. Toyoshima, F., Moriguchi, T., and Nishida, E. (1997) Fas induces cytoplasmic apoptotic responses and activation of the MKK7. JNK/SAPK and MKK6-p38 pathways independent of CPP32like proteases. J. Cell Biol. 139, 1005-1015 